\title{
PENGETAHUAN PERAWAT TENTANG \\ PENYAKIT AKIBAT KERJA PADA PERAWAT
}

\author{
Rahel Juliana Benedikta Berutu
}

Email : beruturahel1507@gmail.com

\section{LATAR BELAKANG}

Pengetahuan adalah merupakan hasil "tahu" dan ini terjadi setelah orang mengadakan pengindraan terhadap suatu objek tertentu. Pengindraan terhadap objek terjadi melalui pancaindra manusia yakni penglihatan, pendengaran, penciuman, rasa dan raba dengan sendiri. Pada waktu pengindraan sampai menghasilkan pengetahuan tersebut sangat dipengaruhi oleh intensitas perhatian persepsi terhadap obyeksebagian besar pengetahuan manusia diperoleh melalui mata dan telinga. Pengetahuan itu sendiri dipengaruhi oleh faktor pendidikan formal. Pengetahuan sangat erat hubungannya dengan pendidikan, dimana diharapkan bahwa dengan pendidikan yang tinggi maka orang tersebut akan semakin luas pula pengetahuannya. Akan tetapi perlu ditekankan, bukan berarti seseorang yang berpendidikan rendah mutlak berpengetahuan rendah pula. Hal ini mengingat bahwa peningkatan pengetahuan tidak mutlak diperoleh dari pendidikan non formal saja, akan tetapi dapat diperoleh melalui pendidikan non formal. Pengetahuan seseorang tentang suatu objek mangandung dua aspek yaitu aspek positif dan aspek negatif. Kedua aspek ini yang akan menentukan sikap seseorang, semakin banyak aspek positif dan objek yang diketahui, maka akan menimbulkan sikap makin positif terhadap objek tertentu. perawat yang tingkat pengetahuannya kurang akan mengalami resiko kecelakaan kerja karena perawat yang berpengatahuan kurang tidak mengetahui resiko kecelakaan kerja serta perundang-undangan keselamatan dan kesehatan kerja.

Penyakit karena kerja bisa menyerang semua tenaga kerja di dalam rumah sakit, baik tenaga medis ataupun non medis karena pajanan biologi, kimia serta fisik di lingkungan kerja rumah sakit tersebut.Penyakit karena kerja adalah seuatu kendala pada tingkat keamanan dalam kerja, dalam perihal ini memerlukan usaha pencegahan, baik untuk keselamatan ataupun kesehatan beberapa pekerja yang berada di lingkungan rumahsakit. Penyakit karena kerja atau terkait dengan pekerjaan bisa dikarenakan oleh pemajanan di lingkungan kerja dengan terus menerus setiap hari.Penyakit Akibat Kerja adalah setiap penyakit yang disebabkan oleh pekerjaan atas lingkungan kerja (Permennakertrans No. PER/01/MEN 1981 dalam Santoso, 2012). Penyakit yang disebabkan hubungan dengan faktor penyebab spesifik di tempat kerja yang sepenuhnya dapat dipastikan dan faktor tersebut dapat diidentifikasi diukur dan selanjutnya dapat dikendalikan (WHO, dalam Santoso, 2012).

Penyakit karena kerja adalah seuatu kendala pada tingkat keamanan dalam kerja, dalam perihal ini memerlukan usaha pencegahan, baik untuk keselamatan ataupun kesehatan beberapa pekerja yang berada di lingkungan rumah sakit. Penyakit karena kerja atau terkait dengan pekerjaan bisa dikarenakan oleh pemajanan di lingkungan kerja dengan terus menerus setiap hari. Untuk menghadapi perihal ini, maka langkah awal yang terpenting ialah pengenalan/identifikasi bahaya yang dapat muncul serta dievaluasi, lalu dikerjakan usaha pengendalian lewat cara melihat serta mengenal (walk through inspections). 
Dalam lingkungan kerja seseorang bisa terganggu kesehatannya, serta gangguan kesehatan karena lingkungn kerja ini cukuplah banyak berlangsung. Penyakit karena kerja diantaranya berlangsung disebabkan karena situasi keadaan kerja seperti udara dingin, panas, bising, bahan kimia, debu dan sebagainya. Gangguan kesehatan pada pekerja bisa juga dipicu oleh aspek yang terkait dengan pekerjaan ataupun aspek yang tidak terkait dengan pekerjaan. Dengan begitu bisa dikatakan jika status kesehatan penduduk pekerja di pengaruhi bukan hanya oleh bahaya di lingkungan kerja tapi ikut oleh aspek kesehatan pekerja yang akan punya pengaruh pada perilaku pekerja yang tidak konsentrasi.

Kehidupan manusia tidak pernah terlepas dari pekerjaan, apapun jenis pekerjaan selalu dilakukan dalam rangka memenuhi kebutuhan sehari-hari, mulai dari pekerjaan berisiko rendah hingga berisiko tinggi. Disamping itu pemahaman dan penerapan keselamatan dan kesehatan kerja (K3) masih kurang di perhatikan oleh pekerja formal maupun informal. Pada hal faktor K3 sangat penting dan harus diperhatikan oleh pekerja dan hal ini menjadi tanggung jawab bersama, perlu adanya kerja sama antara pemerintah, perusahaan dan pekerja agar terhindar dari Kecelakaan Akibat Kerja (KAK) dan Penyakit Akibat Kerja (PAK). Keselamatan dan Kesehatan Kerja merupakan upaya perlindungan tenaga kerja dari bahaya, penyakit dan kecelakaan akibat kerja maupun lingkungan kerja. Penegakan diagnosis spesifik dan sistem pelaporan penyakit akibat kerja penting dilakukan agar dapat mengurangi dan atau bebas dari kecelakaan kerja dan penyakit akibat kerja yang pada akhirnya dapat meningkatkan efisiensi dan produktivitas kerja.

Kecelakaan kerja pada perawat dianggap sebagai suatu masalah serius karena mengancam kesehatan dan kesejahteraan pasien dan petugas kesehatan secara global (Maria, 2015). Kecelakaan tersebut yang pada akhirnya dapat mempengaruhi produktivitas kerja perawat. Produktivitas kerja yang rendah pada akhirnya berdampak terhadap pelayanan kesehatan yang diberikan oleh rumah sakit. Kecelakaan kerja pada perawat juga terjadi karena lingkungan kerja yang buruk seperti Memperpanjang waktu kerja berlebih ataupun beban kerja yang berlebih dan tidak disertai efesiensi yang tinggi, biasanya terlihat penurunan produktivitas serta kecenderungan untuk timbulnya kelelahan pada perawat. Kelelahan kerja akan menurunkan kinerja dan menambah tingkat kesalahan kerja. meningkatnya kesalahan kerja akan memberikan peluang terjadinya kecelakaan kerja. Dengan demikian perawat perlu mengetahui masalah atau penyakit akibat kerja apasaja yang harus di ketahui oleh perawat.

Kata Kunci : Pengetahuan, Penyakit akibat kerja, Perawat, Kecelakaan Kerja.

\section{METODE}

Metode penulisan yang digunakan dalam penulisan laporan ini adalah literature review. Literature review yang dilakukan berupa telaah pustaka artikel penelitian. Artikel dipublikasikan secara elektronik dan diunduh melalui Google Scholar,science direct, scopus, ebook, dan dari beberapa buku keperawatan.. Kata Kunci yang digunakan yaitu Pengetahuan, Penyakit akibat kerja, Perawat, Kecelakaan Kerja. Kriteria inklusi artikel adalah diterbitkan dari tahun 2012 hingga 2020, dan fulltext. Prosedur pengumpulan data yang digunakan adalah menentukan keyword untuk pencarian literatur yang relevan dengan topik kajian dan melakukan penelusuran mengenai topik relevan

\section{HASIL}

Menurut Jurnal yang berjudul Analisis Risiko Keselamatan dan Kesehatan Kerja Pada Petugas Kebersihan di Rumah Sakit bertujuan untuk mencegah atau mengendalikan risiko yang ada sebenarnya sudah cukup baik dengan menyediakan alat pelindung diri, membekali 
pekerjanya dengan pelatihan, dan memberikan himbauan atau peringatan untuk selalu menjaga kebersihan dan kesehatan diri. Namun masih terjadinya kecelakaan kecil seperti tergores kaca atau steinless pada petugas kebersihan dapat diakibatkan karena kurang berhatihati dalam bekerja dapat juga terjadi karena jenis alat pelindung yang kurang pas untuk pekerjaan tersebut. Oleh karena itu perlu dilakukan peningkatan kesadaran diri pada petugas kebersihan dalam menjaga keselamatan dan kesehatan saat bekerja. Keselamatan dan kesehatan kerja merupakan hal penting yang harus diterapkan di semua tempat kerja, baik pada sektor formal maupun sektor informal. Terlebih bagi tempat kerja yang memiliki risiko atau bahaya yang tinggi, serta dapat menimbulkan kecelakaan kerja maupun penyakit akibat kerja. keselamatan dan kesehatan kerja seharusnya diterapkan pada semua pihak yang terlibat dalam proses kerja, mulai dari tingkat manager sampai dengan karyawan biasa.

Berdasarkan Jurnal yang berjudul KEJADIAN KECELAKAAN KERJA PERAWAT BERDASARKAN TINDAKAN TIDAK AMAN bertujuan untuk perawat agar tetap berupaya meminimalkan faktor-faktor pemungkin dan membekali dirinya dengan meningkatkan pengetahuan melalui seminar, media internet atau buku guna mendapatkan informasi terbaru tentang $\mathrm{K} 3$ sehingga dalam menerapkan asuhan keperawatan selalu memperhatikan budaya kerja K3 secara aman dengan penekanan pada universal precautions. Merekomendasikan kepada pihak manajemen RSPW Malang untuk membuat instrumen safe/unsafe action khusus perawat 2 Mengadakan refreshing SOP baru tiap 3 bulan, training/ pelatihan bagi karyawan baru maupun karyawan lama sehingga dapat meningkatkan kesadaran masing masing individu untuk melatih budaya kerja secara aman (safe act culture). Membuat kebijakan terkait advokasi status kesejahteraan perawat dengan memberikan jaminan kesehatan yang baik melalui pemeriksaan kesehatan pra pekerja, berkala (baik yang sudah terpapar/beresiko ataupun tidak) dan pemeriksaan khusus (termasuk pemeriksaan sebelum pensiun) untuk mengetahui adanya Penyakit Akibat Kerja (PAK) serta penatalaksanaannya dan pemberian Vaksinasi sebagai tindakan pencegahan. Bagi peneliti selanjutnya Menentukan periode waktu penelitian, menggunakan desain comparative dengan metode pengumpulan data: observasi

Jurnal yang berjudul FAKTOR YANG BERHUBUNGAN DENGAN KEJADIAN KECELAKAAN KERJA PADA PERAWAT DI RUANG IGD RSU ANUTAPURA KOTA PALU bertujuan untuk memeberikan pemahaman kepada pembaca bahwa Kebijakan/aturan Kesehatan dan Keselamatan Kerja (K3) adalah suatu pernyataan tertulis yang ditandatangani oleh pengusaha dan/atau pengurus yang memuat seluruh visi dan tujuan perusahaan, komitmen dan tekad melaksanakan kesehatan dan keselamatan kerja, serta kerangka dan program kerja yang mencakup kegiatan perusahaan secara menyeluruh yang bersifat umum atau operasional (12). Kebijakan/peraturan Kesehatan dan Keselamatan Kerja (Health and safety) merupakan persyaratan penting dalam penerapan sistem manajemen K3 dalam perusahaan. Kebijakan K3 ini merupakan bentuk nyata dari komitmen manajemen terhadap K3 yang dituangkan dalam bentuk peryataan tertulis yang memuat pokok-pokok kebijakan perusahaan tentang pelaksanaan keselamatan kerja dalam perusahaan. Kebijakan tertulis ini secara tegas mengandung sikap dan komitmen manajemen K3. Penyusunan kebijakan K3 dilakukan dengan mempertimbangkan hasil tinjauan awal yang telah dilakukan sebelumnya, kemudian melakukan proses konsultasi antara pengurus dan wakil pekerja/buruh

\section{PEMBAHASAN}

Perawat adalah tenaga kesehatan yang paling besar jumlahnya dan paling lama kontak dengan pasien, sehingga sangat berisiko dengan pekerjaannya, namun banyak perawat tidak 
menyadari terhadap risiko yang mengancam dirinya, melupakan keselamatan dan kesehatan kerja (K3).

Pengetahuan adalah merupakan hasil "tahu" dan ini terjadi setelah orang mengadakan pengindraan terhadap suatu objek tertentu. Pengindraan terhadap objek terjadi melalui pancaindra manusia yakni penglihatan, pendengaran, penciuman, rasa dan raba dengan sendiri. Pada waktu pengindraan sampai menghasilkan pengetahuan tersebut sangat dipengaruhi oleh intensitas perhatian persepsi terhadap obyeksebagian besar pengetahuan manusia diperoleh melalui mata dan telinga. Pengetahuan itu sendiri dipengaruhi oleh faktor pendidikan formal. Pengetahuan sangat erat hubungannya dengan pendidikan, dimana diharapkan bahwa dengan pendidikan yang tinggi maka orang tersebut akan semakin luas pula pengetahuannya. Akan tetapi perlu ditekankan, bukan berarti seseorang yang berpendidikan rendah mutlak berpengetahuan rendah pula. Hal ini mengingat bahwa peningkatan pengetahuan tidak mutlak diperoleh dari pendidikan non formal saja, akan tetapi dapat diperoleh melalui pendidikan non formal. Pengetahuan seseorang tentang suatu objek mangandung dua aspek yaitu aspek positif dan aspek negatif. Kedua aspek ini yang akan menentukan sikap seseorang, semakin banyak aspek positif dan objek yang diketahui, maka akan menimbulkan sikap makin positif terhadap objek tertentu. perawat yang tingkat pengetahuannya kurang akan mengalami resiko kecelakaan kerja karena perawat yang berpengatahuan kurang tidak mengetahui resiko kecelakaan kerja serta perundang-undangan keselamatan dan kesehatan kerja.

Penyakit Akibat Kerja adalah penyakit yang disebabkan oleh pekerjaan dan lingkungan kerja. Faktor risiko PAK antara lain: Golongan fisik, kimiawi, biologis atau psikososial di tempat kerja. Faktor tersebut di dalam lingkungan kerja merupakan penyebab yang pokok dan menentukan terjadinya penyakit akibat kerja. Faktor lain seperti kerentanan individual juga berperan dalam perkembangan penyakit di antara pekerja yang terpajan.

Salah satu tempat kerja yang berisiko adalah Rumah Sakit, hal ini karena rumah sakit memiliki potensi terjadinya penyakit infeksi terhadap para karyawan, pasien, bahkan pengunjung. Beberapa contoh penyakit infeksi yang dapat terjadi di Rumah Sakit adalah TB, Hepatitis B, Hepatitis C, dan bahkan berisiko terinfeksi HIV/AIDS. Selain penyakit-penyakit infeksi, di rumah sakit juga memiliki risiko atau bahaya lain yang mempengaruhi situasi dan kondisi di rumah sakit, seperti kecelakaan (meliputi kejadian ledakan, kebakaran, kecelakaan yang diakibatkan adanya masalah pada instalasi listrik, serta faktor-faktor yang dapat menimbulkan cidera lainnya), radiasi, paparan bahan kimia beracun dan berbahaya, gasgas anastesi, gangguan terkait psikis dan ergonomi. Semua potensi bahaya tersebut di atas, jelas dapat mengganggu dan menimbulkan rasa kurang aman dan nyaman bagi pekerja di RS, pasien maupun pengunjung yang ada di lingkungan RS.

Faktor risiko yang dapat menyebabkan terjadinya PAK adalah sebagai berikut:

1. Golongan fisik : Kebisingan dapat mengakibatkan gangguan pada pendengaran sampai dengan Non-induced hearing loss, radiasi (sinar radio aktif) dapat mengakibatkan kelainan darah dan kulit, suhu udara yang tinggi dapat mengakibatkan heat stroke, heat cramps, atau hyperpyrexia. Sedangkan suhu udara yang rendah dapat mengakibatkan frostbite, trenchfoot atau hypothermia, tekanan udara yang tinggi dapat mengakibatkan caison disease dan Pencahayaan yang tidak cukup dapat mengakibatkan kelahan mata. Pencahayaan yang tinggi dapat mengakibatkan timbulnya kecelakaan.

2. Golongan kimia : Debu dapat mengakibatkan pneumokoniosis, uap dapat mengakibatkan metal fume fever, dermatitis dan keracunan, gas dapat mengakibatkan keracunan CO dan $\mathrm{H} 2 \mathrm{~S}$, larutan dapat mengakibatkan dermatitis dan insektisida dapat mengakibatkan keracunan 
3. Golongan infeksi : Anthrax, brucell dan HIV/AIDS

4. Golongan fisiologis : Dapat disebabkan oleh kesalahan kontruksi, mesin, sikap badan yang kurang baik, salah cara melakukan suatu pekerjaan yang dapat mengakibatkan kelelahan fisik bahkan lambat laun dapat menyebabkan perubahan fisik pada tubuh pekerja.

5. Golongan mental : Dapat disebabkan oleh hubungan kerja yang tidak baik atau keadaan pekerjaan yang monoton yang menyebabkan kebosanan.

Diagnosis Penyakit Akibat Kerja Secara teknis penegakan diagnosis dilakukan dengan cara berikut ini:

1. Tentukan diagnosis klinis dengan anamnesis yang baik, pemeriksaan fisik diagnostik dan pemeriksaan penunjang.

2. Tentukan pajanan terhadap faktor risiko dengan melakukan anamnesis mengenai riwayat pekerjaan secara cermat dan teliti yang mencakup: Kapan pertama kali bekerja, sudah berapa lama bekerja, apa yang dikerjakan, bahan yang digunakan, informasi bahan yang digunakan (Material Safety Data Sheet/MSDS), bahan yang diproduksi, jenis bahaya yang ada, jumlah pajanan, kapan mulai timbul gejala, kejadian sama pada pekerja lain, pemakaian alat pelindung diri, cara melakukan pekerjan, pekerjaan lain yang dilakukan, kegemaran (hobi) dan kebiasaan lain (merokok, alkohol)

3. Membandingkan gejala penyakit sewaktu bekerja dan dalam keadaan tidak bekerja a. Pada saat bekerja maka gejala timbul atau menjadi lebih berat, tetapi pada saat tidak bekerja atau istirahat maka gejala berkurang atau hilang b. Perhatikan juga kemungkinan pemajanan di luar tempat kerja c. Informasi tentang ini dapat ditanyakan dalam anamnesis atau dari data penyakit di perusahaan

4. Pemeriksaan fisik yang dilakukan dengan catatan : a. Tanda dan gejala yang muncul mungkin tidak spesifik $b$. Pemeriksaan laboratorium penunjang membantu diagnostik klinis c. Dugan adanya penyakit akibat kerja dilakukan juga melalui pemeriksaan laboratorium khusus atau pemeriksaan biomedis

5. Pemeriksaan laboratorium khusus atau pemeriksaan biomedis a. Seperti pemeriksaan spirometri dan rontgen paru (pneumokoniosispembacaan standar ILO) b. Pemeriksaan audiometrik c. Pemeriksaan hasil metabolit dalam darah atau urin 6. Pemeriksaan atau pengujian lingkungan kerja atau data hygiene perusahaan yang memerlukan: a. Kerja sama dengan tenaga ahli hygiene perusahaan b. Kemampuan mengevaluasi faktor fisik dan kimia berdasarkan data yang ada c. Pengenalan secara langsung sistem kerja, intensitas dan lama pemajanan

7. Konsultasi keahlian medis dan keahlian lain Seringkali penyakit akibat kerja ditentukan setelah ada diagnosis klinis, kemudian dicari faktor penyebabnya di tempat kerja atau melalui pengamatan (penelitian) yang relatif lebih lama, dokter spesialis lainnya, ahli toksikologi dan dokter penasihat (kaitan dengan kompensasi).

Penyebab kecelakaan atau cedera salah satunya adalah kebiasaan dimana terdapat suatu keadaan lingkungan tidak aman (unsafe condition) atau tindakan yang tidak memenuhi keselamatan (unsafe act). Seringkali kecelakaan merupakan kombinasi dari kedua faktor tersebut. Pada penelitian ini kejadian cedera pada perawat bisa terjadi karena dipengaruhi oleh tindakan yang tidak memenuhi keselamatan (unsafe act) dalam hal ini adalah kepatuhan dalam menerapkan pedoman keselamatan kerja. Hal ini sejalan dengan penelitian Hidayat (2013) yang menyatakan bahwa perilaku tidak aman (unsfae action) berpengaruh positif dan signifikan terhadap kecelakaan kerja.

Kecelakaan kerja adalah suatu proses atau keadaan yang mengakibatkan kejadian cidera atau penyakit akibat kerja. Penyakit akibat kerja adalah penyakit yang di sebabkan 
oleh pekerjaan, alat, kerja, bahan, proses maupun lingkungan kerja. Setiap hari perawat kontak langsung dengan pasien dalam waktu cukup lama (6-8 jam/ hari), sehingga selalu terpajan mikroorganisme patogen. Dapat menjadi pembawa infeksi dari satu pasien ke pasien lain, atau perawatn lainnya. Harus sangat berhati-hati (bersama apoteker) bila menyiapkan dan memberikan obat-obatan antineoplastik pada pasien kanker. Selalu mencuci tangan setelah melayani pasien, melepas masker, dan kap (topi perawat) bila memasuki ruangan istirahat atau ruang makan bersama. Bahaya di area kerja tenaga perawat ada 2 yaitu penyakit menular dan tidak menular. Bahaya utama yaitu penyakit menular, cedera otot dan tulang serta gangguan tidur.

\section{Penyakit Menular}

Tenaga perawat kemungkinan melakukan kontak yang berhubungan dengan cairan darah berkuman, cairan tubuh, busa, cairan mulut, cairan urine, kotoran manusia, muntahan dan lain-lain sehingga mendapat penularan. Media penularan yang sering terjadi adalah sebagai berikut : Penularan melalui cairan darah (Hepatitis B, hepatitis C, AIDS), Penularan melalui udara atau busa (Flu menular, TBC, SARS), Penularan melalui kontak tubuh(Penyakit kulit biasa, radang infeksi kulit), dan penyakit melalui mulut atau berkontak dengan cairan urine dan kotoran manusia (radang infeksi perut dan hepatitis A).

2. Sakit otot dan tulang

Tindakan memindahkan pasien, membalikkan dan menepuk-nepuk punggung pasien, latihan penyembuhan, dikarenakan sering mengeluarkan tenaga berlebihan, gerakan yang tidak benar dan berulang ulang, mudah menyebabkan cedera bagian otot dan tulang. Apabila tenaga perawat berusia agak tua, maka akan menambah resiko dan tingkat keseriusan cedera di otot dan tulang.

\section{Gangguan Tidur}

Tenaga perawat perlu waktu sepanjang malam atau waktu yang tidak tentu untuk menjaga pasien, sehingga mudah mengalami kondisi tidur pendek, tidur kurang lelap, kesulitan tidur.

Penyakit atau cedera akibat kecelakaan kerja pada perawat. Dalam pekerjaan seharihari petugas kesehatan selalu di hadapkan pada bahaya-bahaya tertentu, misalnya bahaya infeksius, reagensia yang toxic, peralatan listrik maupun peralatan kesehatan. Secara garis besar bahaya yang di hadapi dalam rumah sakit atau instansi kesehatan dapat di golongkan dalam bahaya kebakaran dan ledakan dari zat/bahan yang mudah terbakar atau meledak (obat-obatan), bahan beracun, korosif dan kaustik, bahaya radiasi, luka bakar, syok akibat aliran listrik, luka sayat akibat benda tajam, bahaya infeksi dan kuman. Pada umumnya bahaya tersebut dapat di hindari dengan usaha-usaha pengamanan antara lain dengan penjelasan, peraturan serta penerapan disiplin kerja. Pada kesempatan ini akan di kemukakan manajemen keselamatan dan kesehatan kerja di rumah sakit/instansi kesehatan.

juan diterapkannya K3RS adalah terciptanya cara kerja, lingkungan kerja yang sehat, aman, nyaman, dan dalam rangka meningkatkan derajat kesehatan karyawan RS. Pengetahuan K3RS yang baik diharapkan mampu menekan angka kecelakaan kerja karena individu tersebut dapat menerapakan tindakan yang sesuai dengan pengetahuan K3 yang dimilikinya. Keselamatan pasien indentik dengan kualitas pelayanan, semakin baik kualitas layanan maka keselamatan pasien juga akan semakin baik. Tujuan pengembangan program Keselamatan pasien (patient safety) di rumah sakit adalah, menciptakan budaya patient safety, memperbaiki akuntabilitas rumah sakit, melakukan pencegahan kejadian yang tidak diinginkan tidak terulang kembali. Salah satukomponen tenaga pelayan kesehatan di rumah sakit adalah perawat. Perawat berinteraksi langsung terhadap pasien dengan intensitas yang paling tinggi dibandingkan dengan komponen yang lainnya. Keselamatan sangat dibutuhkan oleh perawat saat bekerja. Keselamatan merupakan salah satu kebutuhan dasar manusia yang 
harus dipenuhi. Manajemen rumah sakit bertanggung jawab untuk membuat program manajemen risiko yang berkelanjutan untuk mengurangi dan mengidentifikasi kejadian yang tidak diinginkan dan risiko-risiko keselamatan lainnya pada pasien dan staf rumah sakit. Perawat seringkali kurang peduli terhadap bahaya di tempat kerja dan dalam melakukan upaya proteksi diri meskipun perawat tahu hal tersebut dapat membahayakan keehatan dan nyawa perawat.

Keselamatan dan kesehatan kerja bertujuan melindungi pekerja atas keselamatannya agar dapat meningkatkan produktifitas nasional. Menjamin semua pekerja yang berada di tempat kerja menggunakan serta merawat sumber produksi secara aman dan efisien

Jenis dan Ragam Penyakit Akibat Kerja

1. Penyakit Alergi Dapat berupa; Rinitis, Rinosinusitis, Asma, Pneumonitis, aspergilosis akut bronchopulmoner, Hipersensitivitas lateks, penyakit jamur, dermatitis kontak, anafilaksis. Lokasi biasanya di saluran pernafsan dan kulit. Penyebab; bahan kimia, microbiologi, fisis dapat merangsang

interaksi non spesifik atau spesifik.

2. Dermatitis Kontak : Ada 2 jenis yaitu iritan dan allergi Lokasi di kulit

3. Penyakit Paru Dapat berupa : Bronchitis kronis, emfisema, karsinoma bronkus, fibrosis, TBC, mesetelioma, pneumonia, Sarkoidosis. Disebabkan oleh bahan kimia, fisis, microbiologi.

4. Penyakit Hati dan Gastro-intestinal Dapat berupa : kanker lambung dan kanker oesofagus (tambang batubara dan vulkanisir karet), Cirhosis hati(alkohol, karbon tetraklorida, trichloroethylene, kloroform) Disebabkan oleh bahan kimia

5. Penyakit Saluran Urogenital Dapat berupa : gagal ginjal(upa logam cadmium \& merkuri,pelarut organik, pestisida, carbon tetrachlorid), kanker vesica urinaria (karet, manufaktur/bahan pewarna organik, benzidin, 2- naphthylamin).Disebabkan bahan kimia.

6. Penyakit Hematologi Dapat berupa : anemia $(\mathrm{Pb})$, lekemia (benzena) disebabkan bahan kimia

7. Penyakit Kardiovaskuler Disebabkan bahan kimia - Dapat berupa : jantung coroner (karbon disulfida, viscon rayon,gliceril trinitrat, ethylene glicol dinitrat), febrilasi ventricel (trichlorethylene).

8. Gangguan alat reproduksi Dapat berupa : infertilitas (ethylene bromida, benzena, anasthetic gas, timbal, pelarut organic, karbon disulfida, vinyl klorida, chlorophene), kerusakan janin (aneteses gas, mercuri, pelarut organik) keguguran (kerja fisik) Disebabkan bahan kimia dan kerja fisik

9. Penyakit muskuloskeletal Dapat berupa : sindroma Raynaud (getaran $20-400 \mathrm{~Hz}$ ), Carpal turnel syndroma (tekanan yang berulang pada lengan), HNP/sakit punggung (pekerjaan fisik berat, tidak ergonomis) Disebabkan : kerja fisik dan tidak ergonomis.

10. Gangguan telinga Dapat berupa : Penurunan pendengaran (bising diatas NAB) Disebabkan faktor fisik

11. Gangguan Mata Dapat berupa : rasa sakit (penataan pencahayaan), conjungtivitis (sinar UV), katarak (infra merah), gatal (bahan organik hewan, debu padi), iritasi non alergi (chlor, formaldehid). Disebabkan faktor fisik, biologi

12. Gangguan Susunan Syaraf Dapat berupa : pusing, tidak konsentrasi, sering lupa, depresi, neuropati perifer, ataksia serebeler dan penyakit motor neuron (cat, carpet-tile lining, lab. Kimia, petrolium, oli). Disebabkan bahan kimia

13. Stress Dapat berupa : neuropsikiatrik; ansietas, depresi (hubungan kerja kurang baik, monoton, upah kurang, suasana kerja tidak nyaman) Disebabkan faktor mental psikologi 
14. Infeksi Dapat berupa : pneumonia (legionella pada AC), leptospirosis (leptospira pada petani), brucellosis, antrakosis (brucella, antrak pada peternak hewan). Disebabkan oleh faktor biolog

15. Keracunan Dapat berupa keracunan akut (CO, Hidrogen sulfida, hidrogen sianida), kronis (timah hitam, merkuri, pestisida). Disebabkan oleh bahan kimia

Setiap pekerjaan di dunia ini pasti tak ada yang tak berisiko. Kecelakaan dan sakit akibat kerja sudah menjadi risiko setiap orang yang melakukan pekerjaan, baik itu petani, nelayan, buruh pabrik, pekerja tambang, bahkan pegawai kantor sekalipun. Fenomena kecelakaan akibat kerja atau penyakit akibat kerja seperti fenomena gunung es. Hanya sedikit kasus kecelakaan atau penyakit akibat kerja yang dilaporkan, sedangkan kecelakaan atau penyakit akibat kerja yang tidak dilaporkan mungkin dapat lebih besar dari yang dilaporkan. Kerugian akibat kecelakaan kerja tidak hanya dirasakan oleh tenaga kerja itu sendiri, namun juga kepada masyarakat sekitar. Oleh karena itu perlu adanya penerapan sistem manajemen K3 di industri maupun tempat kerja untuk mengurangi resiko kecelakaan akibat kerja

\section{PENUTUP \\ KESIMPULAN}

Kehidupan manusia tidak pernah terlepas dari pekerjaan, apapun jenis pekerjaan selalu dilakukan dalam rangka memenuhi kebutuhan sehari-hari, mulai dari pekerjaan berisiko rendah hingga berisiko tinggi. Disamping itu pemahaman dan penerapan keselamatan dan kesehatan kerja (K3) masih kurang di perhatikan oleh pekerja formal maupun informal. Pada hal faktor K3 sangat penting dan harus diperhatikan oleh pekerja dan hal ini menjadi tanggung jawab bersama, perlu adanya kerja sama antara pemerintah, perusahaan dan pekerja agar terhindar dari Kecelakaan Akibat Kerja (KAK) dan Penyakit Akibat Kerja (PAK).

Keselamatan dan Kesehatan Kerja merupakan upaya perlindungan tenaga kerja dari bahaya, penyakit dan kecelakaan akibat kerja maupun lingkungan kerja. Penegakan diagnosis spesifik dan sistem pelaporan penyakit akibat kerja penting dilakukan agar dapat mengurangi dan atau bebas dari kecelakaan kerja dan penyakit akibat kerja yang pada akhirnya dapat meningkatkan efisiensi dan produktivitas kerja.

\section{SARAN}

Bagi perawat agar tetap berupaya meminimalkan faktor-faktor pemungkin dan membekali dirinya dengan meningkatkan pengetahuan melalui seminar, media internet atau buku guna mendapatkan informasi terbaru tentang $\mathrm{K} 3$ sehingga dalam menerapkan asuhan keperawatan selalu memperhatikan budaya kerja K3 secara aman dengan penekanan pada universal precautions. Merekomendasikan kepada pihak manajemen RSPW Malang untuk membuat instrumen safe/unsafe action khusus perawat 2 Mengadakan refreshing SOP baru tiap 3 bulan, training/ pelatihan bagi karyawan baru maupun karyawan lama sehing ga dapat meningkatkan kesadaran masing masing individu untuk melatih budaya kerja secara aman (safe act culture). Membuat kebijakan terkait advokasi status kesejahteraan perawat dengan memberikan jaminan kesehatan yang baik melalui pemeriksaan kesehatan pra pekerja, berkala (baik yang sudah terpapar/beresiko ataupun tidak) dan pemeriksaan khusus (termasuk pemeriksaan sebelum pensiun) untuk mengetahui adanya Penyakit Akibat Kerja (PAK) serta penatalaksanaannya dan pemberian Vaksinasi sebagai tindakan pencegahan. Bagi peneliti selanjutnya Menentukan periode waktu penelitian, menggunakan desain comparative dengan metode pengumpulan data: observasi 


\section{DAFTAR PUSTAKA}

Azizah, N., Setiawan.,Silaban,G.(2017).HUBUNGAN ANTARA PENGAWASAN, PROSEDUR KERJA DAN KONDISI FISIK DENGAN TERJADINYA KECELAKAAN KERJA PADA PERAWAT DI RUANG RAWAT INAP RUMAH SAKITPERMATA BUNDA MEDAN. Jurnal JUMANTIK Vol. 3 No.2 Desember 2018 Mei 2019

Maria, S., Wiyono, J., Candrawati, E. (2015). KEJADIAN KECELAKAAN KERJA PERAWAT BERDASARKAN TINDAKAN TIDAK AMAN. Jurnal Care Vol. 3, No. 2

Pitoyo, J., Hamarno, R., Sa'adah, E, L . (2017). KEPATUHAN PERAWAT MENERAPKAN PEDOMAN KESELAMATAN KERJA DAN KEJADIAN CEDERA PADA PERAWAT INSTRUMEN DI INSTALASI BEDAH SENTRAL. JURNAL PENDIDIKAN KESEHATAN, VOLUME 6, NO. 2, OKTOBER 2017: 65-70

Ramdan, I., M., Rahman, A. (2017).Analisis Risiko Kesehatan dan Keselamatan Kerja (K3) pada Perawat. Jurnal Keperawatan padjadjaran Vol 5, No 3 (2017)DOI: https://doi.org/10.24198/jkp.v5i3.645 pdf : https://doi.org/10.24198/jkp.v5i3.645.

Salmawati, L., Rasul, M., Napirah, R , M. (2019).FAKTOR YANG BERHUBUNGAN DENGAN KEJADIAN KECELAKAAN KERJA PADA PERAWAT DI RUANG IGD RSU ANUTAPURA KOTA PALU. :JURNAL KESEHATAN MASYARAKAT VOLUME 10 NOMOR 2 (2019), 104-112

Sandewa, S., Adhiwijaya, A. (2014). HUBUNGAN PERILAKU DENGAN RESIKO KECELAKAAN KERJA PADA PERAWAT DI RUANG RAWAT INAP RSUD LABUANG BAJI MAKASSAR. Jurnal Ilmiah Kesehatan Diagnosisi Volume 5 Nomor 4 Tahun 2014 ISSN : 2302-1721

Simamora, R. H. (2017). A strengthening of role of health cadres in BTA-Positive Tuberculosis (TB) case invention through education with module development and video approaches in Medan Padang bulanComunity Health Center, North Sumatera Indonesia. International Journal of Applied Engineering Research, 12(20), 10026-10035.

Simamora, R. H., \&Saragih, E. (2019). Penyuluhankesehatanterhadapmasyarakat: Perawatanpenderitaasamuratdengan media audiovisual. JPPM (JurnalPendidikandanPemberdayaanMasyarakat), 6(1), 24-31.

Suarniti,. P., L. (2015).RISIKO ERGONOMI PENYAKIT AKIBAT KERJA PADA PERAWAT GIGI. Jurnal Kesehatan Gigi, Dental Health Journal Vol 3 No 2

Tukatman., Sulistiawati., Purwaningsih., Nursalam . (2015). ANALISIS KESELAMATAN DAN KESEHATAN KERJA PERAWAT DALAM PENANGANAN PASIEN DI RUMAH 
SAKIT BENYAMIN GULUH KABUPATEN KOLAKA. Jurnal Ners Vol. 10 No. 2 Oktober 2015: 343-347

Yuantari, C., Nadia, H. (2018). Analisis Risiko Keselamatan dan Kesehatan Kerja Pada Petugas Kebersihan di Rumah Sakit. Health Journal,5 (3) (2018)107-116 